\title{
Attention-deficit/hyperactivity disorder and impairment in executive functions: a barrier to weight loss in individuals with obesity?
}

\author{
Samuele Cortese ${ }^{1,2,7^{*}}$, Erika Comencini ${ }^{1}$, Brenda Vincenzi ${ }^{3}$, Mario Speranza ${ }^{4,5}$ and Marco Angriman ${ }^{6}$
}

\begin{abstract}
Background: An increasing body of research points to a significant association of obesity to Attention-Deficit/ Hyperactivity Disorder (ADHD) and deficits in executive functions. There is also preliminary evidence suggesting that children with ADHD may be at risk of obesity in adulthood.

Discussion: In this article, we discuss the evidence showing that ADHD and/or deficits in executive functions are a barrier to a successful weight control in individuals enrolled in weight loss programs. Impairing symptoms of ADHD or deficits in executive functions may foster dysregulated eating behaviors, such as binge eating, emotionallyinduced eating or eating in the absence of hunger, which, in turn, may contribute to unsuccessful weight loss. ADHD-related behaviors or neurocognitive impairment may also hamper a regular and structured physical activity. There is initial research showing that treatment of comorbid ADHD and executive functions training significantly improve the outcome of obesity in individuals with comorbid ADHD or impairment in executive functions.

Summary: Preliminary evidence suggests that comorbid ADHD and deficits in executive functions are a barrier to a successful weight loss in individuals involved in obesity treatment programs. If further methodologically sound evidence confirms this relationship, screening and effectively managing comorbid ADHD and/or executive functions deficits in individuals with obesity might have the potential to reduce not only the burden of ADHD but also the obesity epidemics.
\end{abstract}

Keywords: ADHD, Executive functions, Obesity, Treatment resistance

\section{Background}

Attention-Deficit/Hyperactivity Disorder (ADHD) is defined by persistent, age inappropriate and impairing levels of inattention and/or hyperactivity-impulsivity [1]. The Diagnostic and Statistical Manual of Mental Disorders- $4^{\text {th }}$ edition, Text Revision, IV-TR [1] defines four types of ADHD: "predominantly inattentive", "predominantly hyperactive-impulsive", "combined", and "not otherwise specified". Although outside the scope of this article, since the final text is not yet available, we note that the core structure of the diagnostic criteria is largely

\footnotetext{
* Correspondence: samuele.cortese@gmail.com

'Child Neuropsychiatry Unit, G. B. Rossi Hospital, Department of Life Science and Reproduction, Verona University, Verona, Italy

${ }^{2}$ Phyllis Green and Randolph Cowen Institute for Pediatric Neuroscience, Child Study Center of the NYU Langone Medical Center, New York, NY, USA Full list of author information is available at the end of the article
}

unchanged in the forthcoming fifth edition of the diagnostic manual.

ADHD is one of the most frequent childhood-onset psychiatric conditions, with an estimated worldwidepooled prevalence exceeding $5 \%$ in school-age children [2]. Impairing symptoms of ADHD persist into adulthood in up to $65 \%$ of childhood-onset cases [3] and the pooled prevalence of ADHD in adults has been estimated at $\sim 2.5 \%[4]$.

Executive functions are defined as a set of neurocognitive skills that are necessary to plan, monitor and execute a sequence of goal-directed complex actions and include inhibition, working memory, planning, and sustained attention [5]. Besides the behavioural core symptoms of inattention, hyperactivity, and impulsivity, deficits in executive functions are commonly, although not universally, associated with ADHD [6]. Indeed, executive dysfunction is not required for the diagnosis of ADHD, which

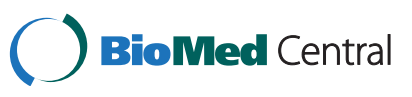


is defined at the behavioral, rather than neuropsychological, level. Additionally, ADHD is usually comorbid with other neurodevelopmental and/or psychiatric conditions, such as learning disorders, oppositional defiant/conduct disorder, mood and anxiety disorders, substance use disorders, and sleep disturbances $[7,8]$.

Currently, the mainstay of treatment, at least for severe cases, is pharmacologic, with psychostimulant medications (methylphenidate and amphetamines) as the first line, and non-stimulants as secondary option [6,9]. Nonpharmacological treatments, such as behavioural therapies, diet regimens, cognitive training, and neurofeedback, are also available. Although the empirical evidence for their efficacy for ADHD core symptoms is so far weak [10], such treatments may effectively address related behavioural or neuropsychological dysfunctions.

Because of its core symptoms as well as associated disorders/conditions, ADHD entails an enormous burden on society in terms of psychological dysfunction, adverse vocational outcomes, stress on families, and societal financial costs. The U.S. annual incremental costs of ADHD have been recently estimated at \$143-\$266 billion [11] and high costs have been reported in other countries as well (e.g., [12]).

Whereas the comorbidity between ADHD and psychiatric disorders has been extensively explored [7], the association with general medical conditions has received much less attention. However, among medical disorders, there is increasing evidence pointing to a significant association between overweight/obesity and ADHD in children $[13,14]$ as well as in adults [15-17]. In particular, as detailed in a previous systematic review [18] and outlined in Table 1, all currently available studies show significantly higher rates of ADHD in individuals with obesity treated in specialized centres compared to normal weight controls or population rates of ADHD. (Studies listed in Table 1 were retrieved searching Pubmed, Ovid, EMBASE, and Web of Knowledge, from their inception to March $15^{\text {th }}$, 2013, using the following keywords, in multiple combination combination: obesity, BMI, weight, body mass, ADHD, Attention-Deficit/Hyperactivity Disorder, Attention Deficit Disorder, Hyperkinetic Disorder; details of the search strategy and syntax, adapted for each database, as well as of the specific results from each database search, are available from the corresponding author). Given the cross-sectional design of such studies, they cannot allow to infer the causal relationship between obesity and ADHD. Theoretically, it is possible that: 1) ADHD contributes to weight gain; 2) Obesity early in life fosters symptoms of ADHD; 3) Both conditions are the expression of underlying neurobiological and psychopathological dysfunctions. Recent studies have shaded light on the causal relationship between ADHD and obesity, supporting in part the notion that ADHD in childhood may contribute to weight gain later on in life. Cortese et al. [19] assessed body mass index (BMI) and obesity rates in a sample of 111 U.S. adults with childhood problems consistent with DSM-IV(-TR) ADHD, combined type, followed up for

\section{Table 1 Studies assessing the rates of Attention-Deficit/Hyperactivity Disorder (ADHD) in clinical samples of} treatment-seeking individuals with obesity

\begin{tabular}{|c|c|c|}
\hline First author (year) [ref] & Sample characteristics & Key findings \\
\hline Altfas (2004) [21] & $\begin{array}{l}215 \text { patients with obesity treated in a specialized } \\
\text { obesity clinic (Males: 22; mean age: } 43.4 \pm 10.9 \text { years) }\end{array}$ & $\begin{array}{l}\text { Prevalence of ADHD in the whole sample: } 27.4 \% \text {. } \\
\text { Prevalence of ADHD in individuals with BMI } \geq 40 \mathrm{~kg} / \mathrm{m}^{2} \text { : } \\
\text { 42.6\%. Mean BMl loss among patients with ADHD: } 2.6 \mathrm{BMl} \\
\left(\mathrm{kg} / \mathrm{m}^{2}\right) \text { vs. } 4.0 \text { for non-ADHD }(p<0.002)\end{array}$ \\
\hline Erermis (2004) [22] & $\begin{array}{c}30 \text { adolescents with obesity (Males: } 14 \text {; mean age: } 13.8 \pm \\
1.2 \text { years) seeking treatment in a paediatric endocrinology } \\
\text { outpatient clinic }\end{array}$ & Prevalence of ADHD: $13.3 \%$ \\
\hline Agranat-Meged (2005) [23] & $\begin{array}{l}26 \text { adolescents in a tertiary referral centre for obesity } \\
\text { (Males: } 13 \text {; mean age: } 13.04 \pm 2.8 \text { years ), all with } \\
\text { morbid obesity (BMI > } 95 \text { percentile) }\end{array}$ & $\begin{array}{l}57.7 \% \text { of the subjects presented with ADHD diagnosed with } \\
\text { semi-structured interviews }\end{array}$ \\
\hline Fleming (2005) [24] & $\begin{array}{c}75 \text { women with severe obesity }\left(\mathrm{BMI} \geq 35 \mathrm{~kg} / \mathrm{m}^{2}\right) \\
\text { (mean age: } 40.4 \pm 7.25 \text { years) referred for non surgical } \\
\text { treatment of obesity }\end{array}$ & $\begin{array}{c}26.7 \% \text { of women reported impairing symptoms of ADHD in } \\
\text { both childhood and adulthood }\end{array}$ \\
\hline Alfonsson (2012) [25] & $\begin{array}{l}187 \text { individuals (Males: } 50 \text {; mean age: } 44.28 \pm 6.02 \text { years) } \\
\text { with obesity, candidate for bariatric surgery }\end{array}$ & $\begin{array}{l}10 \% \text { of the subjects presented with ADHD. ADHD } \\
\text { symptoms significantly correlated with anxiety, depression, } \\
\text { and disordered eating ("lack of control over eating", "eating } \\
\text { alone because embarrassed", "eating until feeling } \\
\text { uncomfortable", and "feeling guilty after overeating") }\end{array}$ \\
\hline Gruss (2012) [26] & $\begin{array}{l}116 \text { patients (Males: } 31 \text {; mean age: } 44.28 \pm 6.02 \text { years) } \\
\text { candidate for bariatric surgery }\end{array}$ & $\begin{array}{l}12 \% \text { of the patients screened positive for ADHD. Rates of } \\
\text { Binge Eating disorder did not differ between patients with } \\
\text { and without ADHD }\end{array}$ \\
\hline Nazar (2012) [27] & 150 women (mean age: $38.9 \pm$ years) & $\begin{array}{c}\text { Prevalence of ADHD: } 28.3 \% \text {. ADHD was significantly } \\
\text { correlated with more severe binge eating, bulimic } \\
\text { behaviors, and depressive symptoms severity }\end{array}$ \\
\hline
\end{tabular}


33 years, and matched comparisons $(\mathrm{N}=111)$ without childhood ADHD. They found that BMI and obesity rates were significantly higher in individuals with childhood ADHD vs. non ADHD comparisons (41.4\% vs. $21.6 \%$, respectively), even after controlling for possible confounders such as socio-economic status (SES) and comorbid psychiatric disorders associated with obesity, i.e., mood, anxiety, and substance use disorders. However, anthropometric data were not collected in childhood, which prevented the authors from determining whether the association between childhood ADHD and weight status at follow-up in adulthood was attributable to weight status in childhood or whether it developed later. Using a dimensional approach (i.e., considering the intensity of each ADHD symptom) rather than a categorical approach based on the DSM-IV-TR nosography, Fuemmelar et al. [16] found a significant linear relationship between the number of retrospectively reported symptoms of inattention or hyperactivity/impulsivity in childhood and adulthood BMI in a population based sample of 15,197 individuals (National Longitudinal Study of Adolescent Health). Extending such evidence, Cortese et al. [20] analyzed a sample of 34,653 U.S. adults from the National Epidemiologic Survey on Alcohol and Related Conditions and found a significant association between the number of symptoms of inattention, hyperactivity, or impulsivity (retrospectively reported) in childhood and obesity in adulthood. However, after controlling for SES and an extensive set of psychiatric disorders, the association held only in women, thus calling for future studies taking into account possible gender differences. The retrospective report of ADHD symptoms is a limitation of this study.

With regards to executive dysfunctions, there is an emerging literature indicating their possible association with overweigh/obesity. In a recent systematic review [28] including 31 papers limited to children and adolescents, Reinert and colleagues concluded that inhibitory control, assessed with several neuropsychological tests, was the most consistently impaired executive function across studies. About $77 \%$ of the retained studies in children and $73 \%$ of the papers relative to adolescents with obesity reported a significant impairment in this executive function. Additionally, scores on neuropsychological tests assessing inhibitory control were significantly lower $(p<0.01)$ in children with obesity than in normal weight comparisons, when pooling data across studies. Another recent systematic review [29] considering individuals across the lifespan and using a different approach in the selection of the papers, showed that decision making, planning and problem solving were the most compromised domains, although the authors note the high heterogeneity across studies in the methodology and in the selection of the neuropsychological tests.
Summarizing, there is increasing evidence that both ADHD, at least considering samples of treatment-seeking individuals, and deficits in executive functions, even in the absence of a formal diagnosis of ADHD, may be associated with obesity. Additionally, there is preliminary evidence that ADHD may causally contribute to obesity/overweight. However, an important aspect to note is that the impact of ADHD or executive dysfunction on obesity outcome is still underexplored. In the next section, we discuss the preliminary evidence showing that ADHD or executive dysfunction may represent an important barrier to successful weight loss in patients with obesity during weight loss programs. We also point out the clinical implications of these findings, as well as possible future research directions in this emerging area of investigation.

\section{Discussion}

Several possible dysfunctional behavioural pathways associated with either ADHD (as a categorical diagnosis) or related neuropsychological deficits in executive functions lead to hypothesize that impairing symptoms of impulsivity, inattention or hyperactivity (the behavioural core symptoms of ADHD) and/or related neurocognitive impairment may be a barrier to successful weight loss during treatment interventions for individuals with obesity.

First, it is possible that impulsivity and deficient neurocognitive inhibitory control foster impulsive and dysregulated eating behaviors, which, in turn, would hamper the success of dietetic regimen. These abnormal eating behaviors include binge eating, "external eating" (i.e., eating in response to food-related stimuli, regardless of the internal state of hunger or satiety) and "emotionally-induced eating" (i.e., excessive eating as a response to emotional states), all of which have been related to obesity and overweight $[30,31]$.

Second, another dysfunction related to impulsivity and deficits in inhibitory control, namely altered reward sensitivity, may also contribute to dysregulated eating behaviors. Indeed, a subset of individuals with ADHD present with a preference for small immediate over larger delayed rewards [29,32]. This could therefore hamper dietetic efforts when considering eating-related rewards deriving from appetizing foods.

Third, it has been noted that attention and related executive functions such as planning and organizational skills are important for a successful adhesion to dietetic regimen and regular physical exercise [18], both of which underpin effective and sustained weight control.

The previous hypotheses of a correlation between ADHD symptoms and/or executive function deficits and abnormal eating start being supported by empirical evidence. With regards to ADHD symptoms, Cortese et al. [33] found a significant correlation between 
inattentive and impulsive ADHD symptoms and binge eating behaviors, even after controlling for comorbid depression and anxiety, in a study of 99 consecutively referred severe obese adolescents (12-17 years). By means of structural equation modelling, Davis et al. [30] found a significant correlation between ADHD symptoms and abnormal eating behaviors (including binge eating and emotionally-induced eating) in a sample of healthy adult women (25-46 years). Using the same modelling, Strimas et al. [34] confirmed these results also in a sample of 145 non-clinical adult males.

There is also evidence that deficit in executive dysfunctions are related to abnormal eating behaviors, although causal relationship has not been tested. For example, in a study of 55 women reporting weekly binge eating in the absence of regular compensatory behaviors, Kelly et al. [35] found a significant correlation between frequency of binge eating behaviors and deficit in executive functions such as flexibility in thinking and shifting attention. By means of path analyses, Dempsey et al. [36] confirmed a significant correlation between deficit in executive functions and overeating behaviors in a sample of 135 individuals from the community. This evidence has been extended to young children. Pieper and Laugero [37] recently reported a significant correlation between executive function deficits, measured by means of child-completed tasks and parental as well as teacher reports, and eating in the absence of hunger in a sample of 29 preschool children (3-6 years).

While the correlation of impulsivity and inattention domains to abnormal eating behaviors associated with obesity may be intuitive, one could think that the hyperactive component of ADHD is not involved at all and, actually, it may favour weight loss rather than weight gain. However, it is well known that the motor hyperactivity of ADHD is not constant. Actigraphic measures have shown that motor hyperactivity is modulated by situational variables and may be indistinguishable from normal when there is sufficient stimulation. For example, no significant differences in hyperactivity levels between children with ADHD and healthy comparisons have been detected while watching television, whereas children with ADHD show significantly more hyperactivity during classes at school [38]; it is important to note that children with ADHD have also been shown to watch more television than non ADHD children. Interestingly, psychostimulant medications induce an increase, rather than a decrease, and a normalization of motor activity during physical education, where movement is appropriate and expected [38]. It is also possible that excessive motor activity in the morning during breakfast hampers a correct consumption of breakfast; in turn, skipping breakfast has been shown as a risk factor for weight gain and obesity [39]. Additionally, restlessness during lunch and dinner may decrease regular food consumption during these structured moments, with inappropriate and excessive compensatory calories intake outside meals. Therefore, we hypothesize that the balance between the tendency to overeat in an irregular way following irregular breakfast and meals, from one side, and the inconstant energy expenditure associated with motor hyperactivity in ADHD, on the other side, may explain why ADHD hyperactivity contributes to increase the risk of obesity.

So, if ADHD or related executive functions deficits foster abnormal eating behaviors contributing to obesity, is there evidence supporting that ADHD and executive dysfunction also represent a barrier to effective and lasting weight loss in individuals with obesity? This starts being reported in the literature, although further and more methodologically sound evidence is needed.

In an observational study of 215 adults with obesity in a specialized clinics, Altfas [21] was the first to note that those without comorbid ADHD achieved nearly twice the BMI loss compared to patients with comorbid ADHD, despite the fact that the latter engaged in more visits, thus suggesting a pattern of "taking more time to accomplish less" associated with ADHD. Afterwards, in a study of adults involved in a behavioral weight loss program, Pagoto et al. [40] confirmed that participants with ADHD reported more previous weight loss attempts and lost less weight than those who did not screen positive for ADHD. Another recent study showed that patients presenting for bariatric surgery (BS) with comorbid ADHD had significantly more difficulties in following visits after BS than those without comorbid ADHD [41].

Indirect support to the hypothesis that executive function deficit is a barrier to effective weight control is also provided by a longitudinal prospective study by Speranza et al. [42] who found that alexithymia was a significant predictor of treatment outcome at 3-year follow-up in a sample of youths with eating disorder. Indeed, alexithymia is related to executive function deficits, as summarized in [43].

Given this preliminary literature, a crucial question is whether treatment of ADHD and/or improvement in executive functions are also effective in decreasing/preventing obesity in children with both conditions. There is initial evidence indicating that the answer may be affirmative.

In a study [44] of 242 individuals with a lengthy history of weight loss failure consecutively referred for refractory obesity, 78 patients (32.2\%) screened positive for ADHD. Of these, 65 started pharmacotherapy for ADHD with psychostimulants, in addition to standard management for weight loss, and were followed up for an average of 466 days. Those who refused pharmacological treatment or who did not tolerate it for adverse events $(n=13)$ were 
also followed up, serving as comparisons, and received standard care for weight loss management. At follow-up, individuals who received treatment lost $12.36 \%$ of their initial weight, whereas comparisons gained an average of $2.78 \%(\mathrm{p}<0.001)$. A putative confounder in interpreting these results is the possible anorexigenic effect that may be associated with psychostimulant treatment. However, appetite reduction was evident in the first 4-6 weeks of treatment, but then it diminished and vanished in most of the subjects within 2 months. Therefore, the authors of the study concluded that it is unlikely that the anorexigenic effect of psychostimulants contributed to the weight loss at follow-up, after more than one year from the start of the treatment. A limitation of this study is its design: although the study was controlled, it was not randomized. Indeed, since the pharmacological treatment for ADHD is effective and is recommended in several guidelines, [6,9], for ethical reason it was not possible to randomize participants either to pharmacological treatment or placebo. As such, this study cannot provide high-level evidence. Although a randomized study testing the effects on weight of psychostimulants for ADHD would be challenging, interestingly, there is preliminary evidence from a randomized trial [45] suggesting that the training of executive functions is highly effective to improve the outcome of obesity. In this trial, Verbeken and coworkers assessed the effects of executive functions training with video games aimed at improving inhibitory control and working memory. They randomized 44 children (8-14 years) who were in the final part of a 10 - month inpatients treatment program in an obesity centre to either 6-week executive functions training or to standard care for weight control. At 8 weeks after the training, children in the training group showed significantly better weight loss maintenance than those in the standard care group.

\section{Clinical implications}

If further methodologically sound studies confirm that ADHD and/or related executive functions deficits are a barrier to effective weight loss, it would be worthy for the clinicians and professionals involved in the management of obesity to screen for ADHD and impairment in executive functions. We note that professionals involved in the treatment of obesity usually do not have an appropriate knowledge of ADHD and related disorders. A systematic screening and appropriate treatment of ADHD and/or executive functions deficits might not only reduce the burden of ADHD, but also improve the outcome of patients with a past history of weight loss failure. This is particularly relevant in terms of decreasing the stigma associated with obesity. Unfortunately, a common belief manifested not only by the lay public but also by some professionals is that individuals with obesity may fail to succeed at weightloss programs due to their "laziness" [46]. Inattention and related impaired executive functions, as well as impulsivity that hamper the appropriate adherence to a regular diet regimen, might be mistakenly attributed to laziness and "character problems". Therefore, awareness that unsuccessful weight loss may be due, at least in part, to neurocognitive impairment could contribute to decrease the stigma associated with obesity.

\section{Future research in the field}

We believe that the relationship between ADHD/executive functions and obesity, as well as the impact of neurocognitive impairment on weight loss management, is still in a developing phase. While the cross-sectional relationship between ADHD and obesity starts being well characterized from a clinical descriptive standpoint, further longitudinal studies are needed to better assess the causal relationship. Studies aimed at elucidating common neurobiological and genetics underpinnings are still in their infancy (e.g., [47]) and need further attention. Perhaps even more important in terms of implementation science would be to assess, by means of rigorous randomized controlled trials, the effects of ADHD treatment or executive functions training on weight outcome in individuals enrolled in weight loss programs. In particular, it would be highly relevant to establish if early management of ADHD in young children leads to further better obesity outcome later on. However, given the challenges, from an ethical standpoint, of conducting long-term randomized controlled trials where participants are assigned either to an effective treatment for ADHD or to placebo, longitudinal studies comparing the weight outcome of obese children treated with ADHD medications vs those who opt for non pharmacological approaches or no treatment, matched for baseline BMI and socio economic status, could provide useful data. This design will likely require multi-center recruitment. Research in such area is worthy and could contribute to decrease the worldwide obesity epidemics.

\section{Summary}

Preliminary evidence suggests that comorbid ADHD and deficits in executive functions are a barrier to a successful weight loss in individuals involved in obesity treatment programs. If further methodologically sound evidence confirms this relationship, screening and effectively managing comorbid ADHD and/or executive functions deficits in individuals with obesity might have the potential to reduce not only the burden of ADHD but also the obesity epidemics.

\section{Abbreviations}

ADHD: Attention-Deficit/Hyperactivity Disorder; BMI: Body mass index SES: Socioeconomic status.

\section{Competing interests}

Dr. Cortese has received financial support to attend medical meetings from Eli Lilly \& Company (2008) and Shire Pharmaceuticals (2009-2010), and has 
been co-investigator in studies sponsored by GlaxoSmithKline (2007), Eli Lilly \& Company (2008), and Genopharm (2009). He has served as scientific consultant for Shire Pharmaceuticals (2009-2010). Drs. Comencini, Vincenzi, Speranza, and Angriman declare no competing conflict of interest.

\section{Authors' contributions}

Dr. Cortese conceived and drafter the manuscript and approved the final version to be submitted; Drs. Comencini, Vincenzi, Speranza, and Angriman critically revised the first draft, contributed to the literature search, and approved the final version to be submitted. All authors read and approved the final manuscript.

\section{Authors' information}

Dr. Cortese is a post doctoral fellow at the Institute for Pediatric Neuroscience, New York University, New York, NY, USA and at the Child Neuropsychiatry Unit, Verona University, Italy. His research interests focus on $A D H D$, in particular on the neurobiology and on the evidence-based treatment of ADHD. Dr. Comencini is a resident in child psychiatry at the Child Neuropsychiatry Unit, Verona University, Italy. Her research focuses on the psychopathology of children with obesity. Dr. Vincenzi is a research fellow at the Massachusetts General Hospital, Schizophrenia Clinical and Research Program, Boston, MA, USA. Her research focuses on eating disorders and schizophrenia. Dr. Speranza is a consultant at the Child and Adolescent Psychiatry, Versailles General Hospital. Le Chesnay, France and a researcher at the University of Versailles Saint-Quentin-en-Yvelines, Versailles, France. His research focuses on eating disorders, ADHD, and personality disorders. Dr. Angriman is a consultant at the Child Neurology and Neurorehabilitation Unit, Department of Pediatrics, Central Hospital of Bolzano, Italy. His research focuses on ADHD, obesity, and sleep disorders.

\section{Acknowledgments}

Dr. Cortese was supported by a "Marie Curie" grant for Career Development International Outgoing Fellowship, PIOF-253103 from the European Commission

\section{Author details}

${ }^{1}$ Child Neuropsychiatry Unit, G. B. Rossi Hospital, Department of Life Science and Reproduction, Verona University, Verona, Italy. ${ }^{2}$ Phyllis Green and Randolph Cowen Institute for Pediatric Neuroscience, Child Study Center of the NYU Langone Medical Center, New York, NY, USA. ${ }^{3}$ Massachusetts General Hospital, Schizophrenia Clinical and Research Program, Boston, MA, USA. ${ }^{4}$ EA4047, University of Versailles Saint-Quentin-en-Yvelines, Versailles, France. ${ }^{5}$ Child and Adolescent Psychiatry, Versailles General Hospital, Le Chesnay, France. ${ }^{6}$ Child Neurology and Neurorehabilitation Unit, Department of Pediatrics, Central Hospital of Bolzano, Bolzano, Italy. ${ }^{7}$ Unità Autonoma di Neuropsichiatria Infantile, Ospedale G.B . Rossi, P.le L.A. Scuro, 12, Verona 37134, Italy.

\section{Received: 31 March 2013 Accepted: 15 July 2013}

Published: 7 November 2013

\section{References}

1. American Psychiatric Association: Diagnostic and statistical manual of mental disorders, 4th ed. Text revision. Washington DC: American Psychiatric Association; 2000.

2. Polanczyk G, de Lima MS, Horta BL, Biederman J, Rohde LA: The worldwide prevalence of ADHD: a systematic review and metaregression analysis. Am J Psychiatry 2007, 164:942-948.

3. Faraone SV, Biederman J, Mick E: The age-dependent decline of attention deficit hyperactivity disorder: a meta-analysis of follow-up studies. Psychol Med 2006, 36:159-165.

4. Simon V, Czobor P, Balint S, Meszaros A, Bitter I: Prevalence and correlates of adult attention-deficit hyperactivity disorder: meta-analysis. BrJ Psychiatry 2009, 194:204-211.

5. Willcutt EG, Doyle AE, Nigg JT, Faraone SV, Pennington BF: Validity of the executive function theory of attention-deficit/hyperactivity disorder: a meta-analytic review. Biol Psychiatry 2005, 57:1336-1346.

6. Pliszka S: Practice parameter for the assessment and treatment of children and adolescents with attention-deficit/hyperactivity disorder. J Am Acad Child Adolesc Psychiatry 2007, 46:894-921.
7. Biederman J, Faraone SV: Attention-deficit hyperactivity disorder. Lancet 2005, 366:237-248.

8. Cortese S, Faraone SV, Konofal E, Lecendreux M: Sleep in children with attention-deficit/hyperactivity disorder: meta-analysis of subjective and objective studies. J Am Acad Child Adolesc Psychiatry 2009, 48:894-908.

9. Taylor E, Dopfner M, Sergeant J, Asherson P, Banaschewski T, Buitelaar J, Coghill D, Danckaerts M, Rothenberger A, Sonuga-Barke E, Steinhausen HC, Zuddas A: European clinical guidelines for hyperkinetic disorder - first upgrade. Eur Child Adolesc Psychiatry 2004, 13(Suppl 1):17-30.

10. Sonuga-Barke EJ, Brandeis D, Cortese S, Daley D, Ferrin M, Holtmann M, Stevenson J, Danckaerts M, van der Oord S, Dopfner M, Dittmann RW, Simonoff E, Zuddas A, Banaschewski T, Buitelaar J, Coghill D, Hollis C, Konofal E, Lecendreux M, Wong IC, Sergeant J: Nonpharmacological interventions for ADHD: systematic review and meta-analyses of randomized controlled trials of dietary and psychological treatments. Am J Psychiatry 2013, 170:275-289.

11. Doshi JA, Hodgkins P, Kahle J, Sikirica V, Cangelosi MJ, Setyawan J, Erder MH, Neumann PJ: Economic impact of childhood and adult attention-deficit/ hyperactivity disorder in the United States. J Am Acad Child Adolesc Psychiatry 2012, 51:990-1002.

12. Hakkaart-van RL, Zwirs BW, Bouwmans C, Tan SS, Schulpen TW, Vlasveld L, Buitelaar JK: Societal costs and quality of life of children suffering from attention deficient hyperactivity disorder (ADHD). Eur Child Adolesc Psychiatry 2007, 16:316-326.

13. Cortese S, Morcillo PC: Comorbidity between ADHD and obesity: exploring shared mechanisms and clinical implications. Postgrad Med 2010, 122:88-96.

14. Cortese S, Vincenzi B: Obesity and ADHD: Clinical and Neurobiological Implications. Curr Top Behav Neurosci 2012, 9:199-218.

15. de Zwaan M, Gruss B, Muller A, Graap H, Martin A, Glaesmer H, Hilbert A, Philipsen A: The estimated prevalence and correlates of adult ADHD in a German community sample. Eur Arch Psychiatry Clin Neurosci 2012, 262:79-86.

16. Fuemmeler BF, Ostbye T, Yang C, McClernon FJ, Kollins SH: Association between attention-deficit/hyperactivity disorder symptoms and obesity and hypertension in early adulthood: a population-based study. Int J Obes (Lond) 2011, 35:852-862.

17. Pagoto SL, Curtin C, Lemon SC, Bandini LG, Schneider KL, Bodenlos JS, Ma Y: Association between adult attention deficit/hyperactivity disorder and obesity in the US population. Obesity (Silver Spring) 2009, 17:539-544.

18. Cortese $S$, Angriman $M$, Maffeis $C$, Isnard $P$, Konofal E, Lecendreux $M$, Purper-Ouakil D, Vincenzi B, Bernardina BD, Mouren MC: Attention-deficit/ hyperactivity disorder (ADHD) and obesity: a systematic review of the literature. Crit Rev Food Sci Nutr 2008, 48:524-537.

19. Cortese S, Ramos-Olazagasti M, Klein R, Castellanos F, Proal E, Mannuzza S: Obesity in Men with childhood ADHD: a 33-year controlled, prospective, follow-up study. Pediatrics 2013. in press.

20. Cortese S, Faraone S, Bernardi S, Wang S, Blanco C: An epidemiologic study of adult attention-deficit/hyperactivity disorder and obesity. $\mathrm{Br} J$ Psychiatry 2013. in press.

21. Altfas JR: Prevalence of attention deficit/hyperactivity disorder among adults in obesity treatment. BMC Psychiatry 2002, 2:9.

22. Erermis S, Cetin N, Tamar M, Bukusoglu N, Akdeniz F, Goksen D: Is obesity a risk factor for psychopathology among adolescents? Pediatr Int 2004, 46:296-301.

23. Agranat-Meged AN, Deitcher C, Goldzweig G, Leibenson L, Stein M, Galili-Weisstub E: Childhood obesity and attention deficit/hyperactivity disorder: a newly described comorbidity in obese hospitalized children. Int J Eat Disord 2005, 37:357-359.

24. Fleming JP, Levy LD, Levitan RD: Symptoms of attention deficit hyperactivity disorder in severely obese women. Eat Weight Disord 2005, 10:e10-e13.

25. Alfonsson S, Parling T, Ghaderi A: Screening of adult ADHD among patients presenting for bariatric surgery. Obes Surg 2012, 22:918-926.

26. Gruss B, Mueller A, Horbach T, Martin A, de Zwaan M: Attention-deficit/ hyperactivity disorder in a prebariatric surgery sample. Eur Eat Disord Rev 2012, 20:e103-e107.

27. Nazar BP, Pinna CM, Suwwan R, Duchesne M, Freitas SR, Sergeant J, Mattos $P: A D H D$ rate in obese women with binge eating and bulimic behaviors from a weight-loss clinic. J Atten Disord 2012. in press.

28. Reinert KR, Po'e EK, Barkin SL: The relationship between executive function and obesity in children and adolescents: a systematic literature review. J Obes 2013, 2013:820956. 
29. Fitzpatrick S, Gilbert S, Serpell L: Systematic review: Are overweight and obese individuals impaired on behavioural tasks of executive functioning. Neuropsychol Rev 2013. in prss.

30. Davis C, Levitan RD, Smith M, Tweed S, Curtis C: Associations among overeating, overweight, and attention deficit/hyperactivity disorder: a structural equation modelling approach. Eat Behav 2006, 7:266-274.

31. van Strien T, Frijters J, Berges G, Defares P: The Dutch Eating Behavior Questionnaire (DEBQ) for assessment of restrained, emotional, and external eating behavior. Eat Dis 1986, 5:295-315.

32. Luman M, Tripp G, Scheres A: Identifying the neurobiology of altered reinforcement sensitivity in ADHD: a review and research agenda. Neurosci Biobehav Rev 2010, 34:744-754.

33. Cortese S, Isnard P, Frelut ML, Michel G, Quantin L, Guedeney A, Falissard B, Acquaviva E, Dalla BB, Mouren MC: Association between symptoms of attention-deficit/hyperactivity disorder and bulimic behaviors in a clinical sample of severely obese adolescents. Int J Obes (Lond) 2007, 31:340-346.

34. Strimas R, Davis C, Patte K, Curtis C, Reid C, McCool C: Symptoms of attention-deficit/hyperactivity disorder, overeating, and body mass index in men. Eat Behav 2008, 9:516-518.

35. Kelly NR, Bulik CM, Mazzeo SE: Executive functioning and behavioral impulsivity of young women who binge eat. Int J Eat Disord 2013, 46:127-139.

36. Dempsey A, Dyehouse J, Schafer J: The relationship between executive function, AD/HD, overeating, and obesity. West J Nurs Res 2011, 33:609-29.

37. Pieper JR, Laugero KD: Preschool children with lower executive function may be more vulnerable to emotional-based eating in the absence of hunger. Appetite 2013, 62:103-109.

38. Porrino LJ, Rapoport JL, Behar D, Ismond DR, Bunney WE Jr: A naturalistic assessment of the motor activity of hyperactive boys. II. Stimulant drug effects. Arch Gen Psychiatry 1983, 40:688-693.

39. Tin SP, Ho SY, Mak KH, Wan KL, Lam TH: Breakfast skipping and change in body mass index in young children. Int J Obes (Lond) 2011, 35:899-906.

40. Pagoto SL, Curtin C, Bandini LG, Anderson SE, Schneider KL, Bodenlos JS, Ma Y: Weight loss following a clinic-based weight loss program among adults with attention deficit/hyperactivity disorder symptoms. Eat Weight Disord 2010, 15:e166-e172.

41. Nicolau J, Ayala L, Francés C, Zubillaga I, Muñiz MJ, Rodriguez I, Gómez LA, Fortuny R, Masmiquel L: Frequency of attention-deficit/hyperactivity disorder (ADHD) in a bariatric post surgery sample: clinical, analytical and psychological differences among bariatric patients with ADHD criteria. Endocrine Abstracts 2013, 32:P777. doi:10.1530/endoabs.32.P777.

42. Speranza M, Loas G, Wallier J, Corcos M: Predictive value of alexithymia in patients with eating disorders: a 3-year prospective study. J Psychosom Res 2007, 63:365-371.

43. Zhang L, Zhu C, Ye R, Cao Z, Tian Y, Yang P, Hu P, Wang K: Impairment of conflict processing in alexithymic individuals. Neurosci Lett 2011, 504:261-264.

44. Levy LD, Fleming JP, Klar D: Treatment of refractory obesity in severely obese adults following management of newly diagnosed attention deficit hyperactivity disorder. Int J Obes (Lond) 2009, 33:326-334.

45. Verbeken S, Braet C, Goossens L, van der Oord S: Executive function training with game elements for obese children: A novel treatment to enhance self-regulatory abilities for weight-control. Behav Res Ther 2013, 51:290-299.

46. Schwartz MB, Chambliss HO, Brownell KD, Blair SN, Billington C: Weight bias among health professionals specializing in obesity. Obes Res 2003, 11:1033-1039.

47. Albayrak O, Putter C, Volckmar AL, Cichon S, Hoffmann P, Nothen MM, Jockel KH, Schreiber S, Wichmann HE, Faraone SV, Neale BM, HerpertzDahlmann B, Lehmkuhl G, Sinzig J, Renner TJ, Romanos M, Warnke A, Lesch KP, Reif A, Schimmelmann BG, Scherag A, Hebebrand J, Hinney A: Common obesity risk alleles in childhood attention-deficit/hyperactivity disorder. Am J Med Genet B Neuropsychiatr Genet 2013. in press.

\section{doi:10.1186/1471-244X-13-286}

Cite this article as: Cortese et al:: Attention-deficit/hyperactivity disorder and impairment in executive functions: a barrier to weight loss in individuals with obesity? BMC Psychiatry 2013 13:286. 